\title{
Carotid Artery Evaluation and its Correlation with White Matter Hyperintensities: A Study Protocol
}

\section{Kaustubh Anil Madurwar ${ }^{1}$, Suresh Vasant Phatak ${ }^{2}$, Chetan Gode ${ }^{3}$}

\author{
Junior Resident, Department of Radiodiagnosis, Jawaharlal Nehru Medical College, Datta Meghe Institute of Medical Sciences (Deemed \\ University), Wardha, Maharashtra, India; 'Professor, Department of Radiodiagnosis, Jawaharlal Nehru Medical College, Datta Meghe lnstitute \\ of Medical Sciences (Deemed University), Wardha, Maharashtra, India; 3Professor, Electronics \& Tele. Engineering, Yeshwantrao Chavan \\ College of Engineering, Nagpur, Maharashtra, India.
}

\section{ABSTRACT}

Background: White matter hyperintensity is an independent and one of the important risk factors than can foresee future stroke and is a very common MRI brain finding. It is one of the most accessible markers to access the effect of vascular hemodynamics on the brain. Carotid Doppler indices have a strong correlation with WMH mainly due to atherosclerotic plaques. Thus these indices we can predict the white matter Hyperintensity burden

Objectives: Study cerebral white matter hyperintensities association with structural and hemodynamic parameters of the carotid artery. To calculate composite intima-media thickness. Evaluate white matter Hyperintensity into low and high burden plaques.

Methodology: 76 patients with white matter hyperintensities will be included in the study subsequent Carotid artery Doppler will be performed to determine various indices which will be later be correlated to MRI findings

Results: Statistical parameters like specificity, sensitivity, accuracy, negative predictive value and positive predictive value of each carotid Doppler value will be correlated to white matter score. ROC curve will be plotted to prove its diagnostic accuracy

Conclusion: Using carotid artery doppler, we can predict the burden of T2/FLAIR white matter ischemic changes in the brain and thus can be used as a predictor of stroke.

Key Words: Carotid Artery, White matter hyperintensities, Composite intima-media thickness

\section{INTRODUCTION}

The wide availability of MRI in recent times has led to increased detection of white matter hyperintensity ${ }^{1}$ and have become a very common finding on MRI Brain. it is an independent and one of the important risk factor than can foresee future stroke. ${ }^{2,3}$ It remains one of the most accessible markers to access the effect of vascular hemodynamic on brain. ${ }^{4}$ Damage to deep sited blood vessels leads to small vessel ischemic changes and the most common cause are the atherosclerotic plaque. ${ }^{5}$ There is a significant correlation between carotid artery indices and white matter ischemic changes

In this present study, Carotid Stenosis and composite intimamedia thickness is large vessel atherosclerosis marker ${ }^{6}$, and internal carotid artery Pulsatility Index (PI) which indicates cerebral microangiopathy is evaluated in association with white matter scores. ${ }^{7}$ Association of white matter scores with the risk factors for cerebral microangiopathy like hypertension, diabetes and dyslipidaemia are also studied. ${ }^{8}$

\section{OBJECTIVES}

- Study cerebral white matter hyperintensities association with structural and hemodynamic parameters of the carotid artery.

- Score the white matter Hyperintensity into low and high burden plaques

- To determine carotid artery composite intima-media thickness and various other parameters.

\section{MATERIALS AND METHODS}

Study design: Cross-sectional study

\section{Corresponding Author:}

Dr. Kaustubh Anil Madurwar, Department of Radiodiagnosis, Jawaharlal Nehru Medical College, Datta Meghe Institute of Medical Sciences (Deemed University), Wardha, Maharashtra, India; Contact: 9619685959; Email: madurwarkaustubh@gmail.com

ISSN: 2231-2196 (Print)

Received: 12.09 .2020
ISSN: $0975-5241$ (Online)

Revised: 18.10 .2020
Accepted: 05.11 .2020

Published: 30.11 .2020 
All patients referred to our Radio diagnosis department for MRI Brain showing white matter hyperintensities over 2 years. After written informed consent from the patients who come for MRI Brain which reveals white matter hyperintensities suggestive of small vessel ischemic changes are included

\section{Exclusion criteria}

1. Patients with a previous history of stroke and intracerebral bleed.

2. Patients with known causes of white matter Hyperintensity like acute demyelinating encephalomyelitis, multiple sclerosis, vasculitis, connective tissue diseases, migraine, major psychiatric disorder, normal pressure hydrocephalus. ${ }^{9}$

3. Post radiotherapy patients.

4. Patients who did not give consent for participating in the study

5. Uncooperative patients in whom MRI brain or carotid artery Doppler cannot be performed.

\section{MRI Brain}

Modified Scheltens scoring system is used to score White matter. Carotid artery composite intima-media thickness, Degree of stenosis and internal carotid artery Pulsatility index will is accessed. Modified Scheltens scoring system includes:

Deep white matter score

- Parietal

- Frontal

- Occipital

- Temporal

Each region has a minimum score of 0 and a maximum scoring of 6

Periventricular white matter score

- Frontal

- Occipital

- Lateral Vertical bands

Each region has a minimum score of 0 and a maximum scoring of 2 .

So total Scoring can range from 0 to 30 , which will further be divided into high and low burden scores.

Carotid artery variables:

1. Composite Intima media thickness

- It is the average of the measurement of IMT of both left and right side's segment of the carotid artery. It includes Common and internal carotid, carotid bulb segment. ${ }^{10}$

2. Plaque

- Any focal or diffuse thickening noted within the artery.
3. Carotid stenosis

- Using an appropriate acoustic angle, It is calculated in terms of the degree of stenosis which percentage the lumen that is occluded due to IMT or Plaque. It is divided into hemodynamically significant and insignificant stenosis. ${ }^{11}$

4. Pulsatility index

- PI of the internal carotid artery will be used. It is calculated automatically by the scanner.

Study size: total sample size is calculated to be 76 patients with white matter hyperintensities by using Chi-Square formula.

$\mathrm{X}^{2}=$ Chi square value is 3.84 at $5 \%$ level of significance

$\mathrm{P}=50 \%$

Proportion $=0.50$

$\mathrm{C}$ : confidence interval of the one choice $(95 \% \mathrm{CI})=0.05$

The prevalence rate for WMH: 94

$$
\begin{aligned}
N & =\frac{3.84 \times 94 \times 0.5 \times 0.5}{0.05^{2} \times 93+3.84 \times 0.5 \times 0.5} \\
& =76
\end{aligned}
$$

Bias: Inter-observer variations will be minimized by taking an average of the 3 reading. The images will be zoomed in at required magnification to minimize error ${ }^{12}$.

\section{EXPECTED OUTCOMES/RESULTS}

In this cross-sectional observational study, white matter score should be more in men and increases as the age advances. Composite IMT will have better indicator than Common carotid IMT and is expected to behave better sensitivity and specificity than other parameters. As the burden of white matter score increases, the Composite IMT increases. Hemodynamically significant stenosis when present, high burden score is expected. hypertension, diabetes, dyslipidemia are most commonly associated risk factors. Among them, Hypertension could be the commonest. We should be able to calculate the diagnostic cut-off value for periventricular, deep and total WMH by using receiver operating characteristic.

\section{DISCUSSION}

Cerebrovascular events are the commonest cause of mortality and morbidity in population especially the elder ones..$^{13}$ With the use of this study, we will determine the burden of white matter in brain which is itself a known risk factor for stroke..$^{14,15}$ In this, we will divide WMH into a low and high burden. Further, they are correlated and statistically analysed. Single centric study leading to bias, since verte- 
bral artery is not evaluated ${ }^{16}$ and only Carotid artery is being evaluated, the lesion and hemodynamically status of them will be skipped which causes many cerebrovascular events especially the posterior circulation. ${ }^{17}$

\section{CONCLUSION}

By use of carotid artery Doppler, we can predict the burden of T2/FLAIR white matter ischemic changes in the brain and thus can be used as a predictor of stroke.

\section{ACKNOWLEDGMENT}

Authors acknowledge the immense help received from the scholars whose articles are cited and included in references to this manuscript. The authors are also grateful to authors / editors / publishers of all those articles, journals, and books from which the literature for this article has been reviewed and discussed.

\section{Conflict of Interest: Nil}

Source of Funding: Nil

\section{REFERENCES}

1. Ovbiagele B, Saver JL. Cerebral white matter hyperintensities on MRI: current concepts and therapeutic implications. Cerebrovasc Dis 2006;22(2-3):83-90.

2. Lechner H, Schmidt R, Bertha G, Justich E, Offenbacher H, Schneider G. Nuclear magnetic resonance image white matter lesions and risk factors for stroke in normal individuals. Stroke $1988 \mathrm{Feb} ; 19(2): 263-5$.

3. Altaf N, Morgan PS, Moody A, MacSweeney ST, Gladman JR, Auer DP. Brain white matter hyperintensities are associated with carotid intraplaque haemorrhage. Radiology 2008 Jul;248(1):202-9.

4. Heliopoulos I, Artemis D, Vadikolias K, Tripsianis G, Piperidou C, Tsivgoulis G. Association of ultrasonographic parameters with subclinical white-matter hyperintensities in hypertensive patients. Cardiovasc Psych Neurol 2012;2012.
5. Lee KY, Sohn YH, Baik JS, Kim GW, Kim JS. Arterial pulsatility as an index of cerebral microangiopathy in diabetes. Stroke 2000;31(5):1111-5.

6. Bhinder HP, Kamble TK. The study of carotid intima-media thickness in prediabetes and its correlation with cardiovascular risk factors. J Datta Meghe Insti Med Sci Uni 2018 Apr;13(2):79.

7. Pantoni L, Garcia JH. Pathogenesis of leukoaraiosis: a review. Stroke 1997;28(3):652-9.

8. Della-Morte D, Dong C, Markert MS, Elkind MS, Sacco RL, Wright CB, et al. Carotid intima-media thickness is associated with white matter hyperintensities: the Northern Manhattan Study. Stroke 2018;49(2):304-11.

9. Ye H, Wang Y, Qiu J, Wu Q, Xu M, Wang J. White matter hyperintensities and their subtypes in patients with carotid artery stenosis: a systematic review and meta-analysis. BMJ Open 2018 May;8(5).

10. Kröner ES, van der Grond J, Westenberg JJ, van der Wall EE, Siebelink HM, Lamb HJ. Morphological and functional carotid vessel wall properties about cerebral white matter lesions in myocardial infarction patients. Netherlands Heart J 2015 Jun;23(6):314-20.

11. Webb AJ, Simoni M, Mazzucco S, Kuker W, Schulz U, Rothwell PM. Increased cerebral arterial pulsatility in patients with leukoaraiosis: arterial stiffness enhances transmission of aortic pulsatility. Stroke 2012 Oct;43(10):2631-6.

12. Pico F, Dufouil C, Lévy C, Besançon V, de Kersaint-Gilly A, Bonithon-Kopp C, et al. Longitudinal study of carotid atherosclerosis and white matter hyperintensities: the EVA-MRI cohort. Cerebrovasc Dis 2002;14(2):109-15.

13. Gawande P, Nayak S, Mudey A, Nagrale A. Assessment of Risk Factor of NCD in Nachangaon Village at Wardha District. Int J Med Res Health Sci 2017;6(4):75-9.

14. Acharya S, Shukla S, Wanjari A. Subclinical Risk Markers for Cardiovascular Disease (CVD) in Metabolically Healthy Obese (MHO) Subjects. J Clin Diagn Res 2019;13(6).

15. Regmi PR, Van Teijlingen E, Mahato P, Aryal N, Jadhav N, Simkhada P, et al. The health of Nepali migrants in India: A qualitative study of lifestyles and risks. Int J Environ Res Public Health 2019;16(19):3655.

16. Walinjkar RS, Khadse S, Kumar S, Bawankule S, Acharya S. Platelet indices as a predictor of microvascular complications in type 2 diabetes. Indian J Endocrinol Metabol 2019;23(2):206.

17. Lahoti S, Kumar S, Agrawal S. Study of carotid intimal medial thickness in chronic kidney disease at rural teaching hospital. Anna Med Health Sci Res 2017;7(6). 